\title{
Upside down crossed cerebellar diaschisis: proposing chronic stimulation of the dentatothalamocortical pathway for post-stroke motor recovery
}

\author{
Andre Machado ${ }^{*}$ and Kenneth B. Baker ${ }^{2}$ \\ 1 Department of Neurosurgery, Center for Neurological Restoration, Neurological Institute, Cleveland Clinic, Cleveland, OH, USA \\ 2 Neurology Department, University of Minnesota, Minneapolis, MN, USA
}

Edited by:

Sridevi V. Sarma, Johns Hopkins University, USA

\section{Reviewed by:}

Hao Zhang, Lancaster University, UK Antonio Pereira, Federal University of Rio Grande do Norte, Brazil

\section{*Correspondence:}

Andre Machado, Department of Neurosurgery, Center for Neurological Restoration, Neurological Institute, Cleveland Clinic, 9500 Euclid Avenue, S31, Cleveland, OH 44195, USA. e-mail:machada@ccf.org

\begin{abstract}
Background: Stroke remains the leading cause for long-term motor impairment in the industrialized world. New techniques are needed to improve outcomes. Objective: To propose chronic electrical stimulation of the dentatothalamocortical pathway as a method for enhancing cortical excitability and improving motor recovery following stroke. Method: In previous studies, motor evoked potentials were derived from intracortical microstimulation and used to index cortical excitability in rats undergoing continuous, asynchronous deep cerebellar stimulation. In a separate set of experiments, the effect of chronic deep cerebellar stimulation on motor recovery was tested in rats following large ischemic strokes. Results: Deep cerebellar stimulation modulated cortical excitability in a frequencydependent fashion. Beta band stimulation yielded sustained increment in excitability and was associated with enhanced motor recovery compared to sham stimulation. Conclusion: Chronic deep cerebellar stimulation enhances recovery of motor function following large ischemic strokes in the rat, an effect that may be associated with increased cortical excitability. Given that deep brain stimulation is already a well established method, this new approach to motor recovery may be a viable option for human translation in stroke rehabilitation.
\end{abstract}

Keywords: stroke, plasticity, deep brain stimulation, electrical stimulation, diaschisis, rehabilitation

\section{INTRODUCTION}

Stroke is a leading cause of disability that significantly impacts quality of life and has high direct and indirect costs to health care and social security systems. Despite progress in acute intervention strategies there continues to be an enormous need for novel approaches to facilitate rehabilitation for patients facing this difficult medical challenge. Currently, several such approaches are being explored at both clinical and preclinical levels, with the general goal of either encouraging assumption of function by surviving tissue or repairing or facilitating growth of neural tissue. Neurorestorative approaches, including intracerebral and systemic injection of growth factors and mesenchymal stem cells (Lin et al., 2011; Savitz et al., 2011) have yielded promising data in animal models, however the translation of these treatments to human use is complicated by limited knowledge of their short- and long-term safety for patients. Neurostimulation-based approaches endeavor to modulate the physiological activity of surviving tissue as a means of encouraging functional reorganization through techniques that can be implemented either non-invasively or invasively. Non-invasive stimulation of the central nervous system, including transcranial magnetic stimulation (TMS) and transcranial direct current stimulation (tDCS), is the subject of active and promising research (Floel and Cohen, 2010). These techniques are likely safe and may play a significant role in prognostication and outpatient rehabilitation but their long-term clinical use during post-stroke recovery may suffer from the limitations of a non-implanted device. Invasive approaches generally involve the surgical implantation of chronic electrodes used to stimulate directly a targeted brain region. A recent example of one such approach involved direct stimulation of peri-motor cortex using implanted, subdural electrode arrays. The approach held great promise for promoting motor rehabilitation following stroke based on preclinical work in animal models (Adkins-Muir and Jones, 2003; Plautz et al., 2003; Adkins et al., 2006, 2008) and early phase trials in humans (Brown et al., 2008; Huang et al., 2008; Levy et al., 2008) however a large randomized clinical trial failed to meet its intended endpoints (Plow et al., 2009). In the current report, we review some lessons learned from recent attempts to translate neurostimulation techniques to stroke rehabilitation in humans and propose a novel method for facilitating post-stroke rehabilitation involving chronic subcortical stimulation of the dentatothalamocortical pathway.

\section{STROKE IS A LEADING CAUSE OF LONG-TERM DISABILITY}

According to the American Stroke Association, approximately 795,000 people suffer strokes in the United States each year (Roger et al., 2011). The majority of those afflicted survive the acute phase, though many sustain substantial, irreversible tissue loss despite recent advances in acute intervention. As a result, it is estimated that approximately $50 \%$ of stroke survivors are left with some degree of hemiparesis, which is the leading reason for post-stroke disability and loss of independence in the United States (Roger 
et al., 2011). Current post-stroke rehabilitation options for patients are limited, with standard of care generally consisting of a few weeks of in-patient and/or outpatient program with additional follow-up sessions available for some patients. Although therapy has been shown to enhance motor outcomes, a large proportion of patients will fail to recover to the point of independence. The economic impact of disability arises both directly, from loss of productivity of the affected individual, and indirectly, due to loss of caregiver productivity in the work force. The American Stroke Association estimated the direct and indirect costs of stroke in 2007 at $\$ 40.9$ billion in the United States alone. Such a high impact on individual health and quality of life as well as on the economy underscores the need for novel therapies aimed at enhancing rehabilitation outcomes and reducing long-term disability and dependence.

\section{MECHANISMS OF MOTOR RECOVERY FOLLOWING STROKE}

The mechanisms underlying post-acute stroke rehabilitation are likely to be associated with plasticity, including vicariation of function to surviving areas of the brain. Current views of postacute motor recovery mechanisms generally emphasize the contributions made by functional reorganization in spared cortical areas in the ipsilesional hemisphere, though changes have been observed in cortical regions contralateral to the affected hemisphere (Johansen-Berg et al., 2002) and these may play a role in the recovery process of at least a subset of stroke patients. Within the affected hemisphere, reorganization following ischemia of the primary motor cortex is not limited to the premotor cortex, or even to other areas within the frontal lobe. Perilesional reorganization in the spared cortex posterior (parietal) to the stroke has been linked to recovery of motor function in the rat. (Kleim et al., 1998) non-human primate (Glees and Cole, 1952; Nudo and Milliken, 1996; Frost et al., 2003) and in humans (Liepert et al., 2000). The incidence of functional reorganization has been linked, in turn, to changes in the excitability of the spared cortical regions. Using TMS, Blicher et al. (2009) found intracortical inhibition to be increased in stroke patients relative to healthy volunteers with its persistence possibly related to functional recovery. A number of other groups have demonstrated changes in perilesional intracortical inhibition and excitability in patients undergoing post-stroke rehabilitative training (Liepert et al., 2001; Liepert, 2006; Butler and Wolf, 2007; Blicher et al., 2009). Furthermore, excitability changes in the perilesional cortex - indexed by TMS generated motor evoked potentials (MEPs) - has been linked to perilesional plasticity as well as motor outcomes (Butler and Wolf, 2007; Theilig et al., 2011). These findings point to a possible strategy for promoting motor recovery via techniques facilitate excitability in spared cortical regions in the context of motor rehabilitation. We propose a novel, titratable, and ultimately reversible method to modulate cortical excitability as a means of potentially enhancing cortical reorganization and improving post-stroke motor recovery by electrically stimulating the dentatothalamocortical pathway.

\section{FACILITATION OF MOTOR REHABILITATION THROUGH DIRECT STIMULATION OF THE PERILESIONAL CORTEX WITH ELECTRICAL OR MAGNETIC STIMULATION}

Electrical stimulation of cerebral cortex was performed for the first time more than 100 years ago (Zago et al., 2008). Penfield and Rasmussen (1950) systematically implemented cortical stimulation to map human cerebral function. Modern techniques now allow for stimulation of the cortex using either invasive or non-invasive methods. The most utilized tool for non-invasive stimulation is TMS, which can be used to deliver either single or trains of magnetic pulses over short periods of time, typically in the outpatient setting. TMS has both research as well as clinical uses, though its clinical utility has practical limitations including the size and complexity of the equipment that allows stimulation to be applied only during regimented sessions while the coil is in a fixed position in relation to the head. Several studies have demonstrated that patients who underwent regular treatment sessions involving TMS, typically in association with motor training, showed a small degree of improvement in motor function relative to non-treated controls (Hummel and Cohen, 2005; Hummel et al., 2005; Takeuchi et al., 2005). These improvements have been attributed to cortical reorganization, including in the perilesional area (Butler and Wolf, 2007). Although TMS modulation of ipsilesional activity has been done mostly with stimulation applied directly to the affected hemisphere, Fregni et al. $(2005,2006)$ have demonstrated that similar results can be accomplished by modulating interhemispheric inhibition. The results thus far with non-invasive stimulation are important because they demonstrate that modulation of ipsilesional activity is possible and can enhance motor recovery, most likely by promoting plastic reorganization of spared cortical areas. However, these results, while statistically significant, have thus far been modest, with limited significance both clinically and with respect to changes in quality of life.

The direct and chronic application of electrical stimuli to specific regions of the brain through implanted medical devices has been possible for several decades (Ray and Burton, 1980; Siegfried et al., 1980). Deep brain stimulation is now standard of care for the management of advanced Parkinson's disease, yielding consistent and significant improvements in parkinsonian motor signs (Follett et al., 2010; Machado et al., 2012). Epidural stimulation of the motor cortex was pioneered in the early 1990s as a treatment for chronic pain (Tsubokawa et al., 1991a,b) with initial reports suggesting not only efficacy for both central pain and peripheral neuropathy but also a modest degree of improvement in motor function. However, cortical stimulation has not become a standard treatment for chronic pain syndromes, though it continues to be offered in some centers for selected patients (Machado et al., 2007). Despite its inconsistent results in the management of pain, there has been a growing interest in its potential use for facilitating motor recovery as part of stroke rehabilitation. This interest has lead to significant efforts in preclinical as well as phase I, II, and III clinical trial research. In preclinical studies, cortical stimulation in a rodent model of relatively small, cortical stroke induced by endothelin injections was associated with significant, frequency-dependent gains in motor function (Adkins et al., 2006). Follow-up studies identified the existence of structural changes in the stimulated, perilesional areas, implicating a plasticity-based mechanism that was congruent with the observed improvement in motor function (Adkins et al., 2008). This approach was evaluated further in trials involving a non-human primate model of stroke induced using a small, cautery lesion of motor cortex resulting in deficits in contralateral forepaw function. Similar to the rodent findings, chronic 
stimulation of peri-motor cortex was associated with both motor improvement and cortical reorganization (Plautz et al., 2003). The approach was translated to human trials and continued to show promise as phase I and II clinical trials demonstrated not only safe implementation of the approach but some evidence of therapeutic efficacy (Brown et al., 2003; Levy et al., 2008; Harvey and Winstein, 2009). Unfortunately, a subsequent, large multicenter, controlled trial failed to identify any significant motor or quality of life benefits in response to the therapy (Plow et al., 2009).

The reason for the lack of success of the phase III trial is not completely clear, though methodological issues, may have contributed to the negative results. Nevertheless, it is also possible that chronic epidural cortical stimulation is not a viable option for post-stroke motor rehabilitation in humans. The disparity between preclinical findings and the final results of clinical translation may be due to fundamental limitations of animal models of stroke as well as inter-species differences in cortical anatomy. With respect to the animal models, lesion volumes in the preclinical rodent and non-human primate models are generally well-controlled and were limited in volume relative to spontaneous infarcts. As such, there is not only proportionally greater areas of spared cortex available for involvement in the reorganization process, but a more consistent pattern of spared cortex between study animals. Human strokes affecting the motor areas, particularly those that show poor spontaneous recovery (and hence more likely to be enrolled in a clinical trial), tend to have larger volumes and thereby less spared perilesional tissue. Additionally, the larger area of the human stroke would require larger cortical stimulation grids to cover spared perilesional regions. From an anatomical perspective, inter-species differences also may have contributed to the lack of translational success. The cerebral cortices of the rodent and non-human primate models (i.e., squirrel monkey) selected are relatively flat in comparison to the profound convolutions found in the human brain, resulting in a more consistent pattern of organization of the pyramidal and inter-neurons across large expanses of cortex. In humans, the orientation of neurons in relation to the dura can vary dramatically depending on their location relative to the crown or sulcus of a gyri. Cathodal and anodal stimulation have different effects on the cortical surface and the orientation of the neuron plays a key role in determining its response to epidural stimulation (Holsheimer et al., 2007; Manola et al., 2007). Hence, it is conceivable that in human clinical trials the effects of epidural stimulation had a net neutral effect or negative effect, or perhaps simply did not achieve a necessary volume of effect, due to this variation in the neuron orientation relative to the epidural stimulating electrodes. One of the potential benefits of the approach proposed herein lies in taking advantage of the dentatothalamocortical pathway fibers directing the effects of stimulation to the perilesional cortical area, regardless of the orientation of neurons in the corresponding gyri.

\section{CROSSED CEREBELLAR DIASCHISIS AND A RATIONALE FOR DENTATOTHALAMOCORTICAL ACTIVATION IN STROKE REHABILITATION}

Diaschisis is a term first coined early in the twentieth century to describe a phenomenon that involved the loss of function in a distant, but anatomically connected, brain region and was thought to be due to a reduction in afferent input from the area of the brain directly affected by pathology (von Monakow, 1950). The clinical impact of this phenomenon is such that the resultant neurological deficits are greater than would be expected from the primary lesion alone. In modern times, the term crossed cerebellar diaschisis (CCD) has been used to describe a phenomenon that occurs in the cerebellar hemisphere contralateral to a cerebral hemisphere that has been damaged by stroke or other disease processes (Pantano et al., 1986, 1987; Reivich, 1992; Baron, 1993; Nathan et al., 1994; Flores et al., 1995; Abe et al., 1997; De Reuck et al., 1997; Ishihara et al., 1999; Srinivasan et al., 2004). Neuroimaging studies evaluating CCD suggest that the cerebellum suffers a reduction in activity, metabolism, and blood flow secondary to the loss of input from the damaged contralateral cerebral hemisphere (Brunberg et al., 1992; Tanaka et al., 1992; Miura et al., 1994; De Reuck et al., 1997) mediated by degeneration of the corticopontocerebellar pathway. This phenomenon highlights the magnitude of the connectivity and input interdependence between the cerebral cortex and contralateral cerebellar hemisphere and forms the basis for the therapeutic approach that we propose.

Just as the activity of the cerebellar hemisphere depends on descending input from the contralateral cerebral cortex, the activity and excitability of the cerebral cortex is dependent upon ascending input originating in the contralateral cerebellum. TMS studies have demonstrated that damage to the cerebellothalamocortical pathway reduces cerebral cortex excitability chronically (Di Lazzaro et al., 1994b, 1995). Furthermore, CCD has been linked to poor outcome following stroke (Kim et al., 1997; Lin, 1997; Seitz et al., 1998) though whether it plays a role in interfering with the potential for motor recovery or merely represents an epiphenomenon that occurs in patients who already had a poor prognosis due to their initial injuries is not yet clear. In an effort to address this issue, Takasawa et al. (2002) evaluated the recovery of stroke patients at 60 days and correlated patient outcome to the severity of CCD. Although there was no correlation between 60day outcome and CCD in the acute phase, a significant correlation was identified between CCD in the early subacute phase and 60day outcome measured by the Scandinavian stroke scale, Barthel index and the recovery index. The negative effect of CCD on motor recovery may be the result of a lack of tonic, excitatory input from the hypoactive cerebellum to cortex via the motor thalamus. In our approach, we propose that stimulation of the dentatothalamocortical pathway will tonically activate cerebellar output, thereby up-regulating thalamocortical activity and enhancing excitability in perilesional cortex. Given that stimulation is delivered directly to the deep cerebellar nuclei, activity downstream in the thalamus will be upregulated regardless of the degree of CCD-related cerebellar hypoactivity. Consequently, this approach also may act to reverse the negative effects of CCD. One important hypothetical feature of this approach is utilizing the natural fiber pathway, discussed in more detail below, to activate the cortex via "upstream" stimulation. Unlike epidural stimulation this approach allows - in principle - for layer-specific cortical facilitation regardless of the anatomic location of the perilesional tissue in relation to a gyrus or sulcus or the geometric orientation of the neurons in relation to cortical convexities. 


\section{THE DENTATOTHALAMOCORTICAL PATHWAY AS A THERAPEUTIC TARGET IN STROKE REHABILITATION}

The cerebral cortex is tightly and reciprocally linked to the contralateral cerebellum, with the ascending and descending components of the circuit consisting primarily of the dentatothalamocortical and corticopontocerebellar pathways, respectively. The dentatothalamocortical pathway is a disynaptic excitatory pathway originating in the dentate nucleus. Upon emerging from the cerebellum via the superior cerebellar peduncle, its fibers decussate at the level of the inferior colliculus, surround the contralateral red nucleus, and terminate across the ventroposterolateral pars oralis (VPLo), mediodorsal (MD), and ventrolateral pars caudalis (VLc) nuclei of the thalamus. These thalamic nuclei project, in turn, to primary motor cortex as well as to areas 2 and 3 of somatosensory cortex (Tracey et al., 1980). Although initial reports regarding the terminations of the dentatothalamocortical pathway at the level of the cerebral cortex emphasized these sensorimotor regions, a situation that would limit its potential utility for promoting functional reorganization in the face of motor cortical infarct, recent odological studies have demonstrated that its projections go beyond the motor cortex and also include premotor and posterior parietal terminations (Dum et al., 2002; Dum and Strick, 2003). Such areas represent the typical perilesional zone that survives following a middle cerebral artery ischemic stroke, leaving open the possibility of using stimulation of this pathway to enhance excitability not only in the area likely to be primarily affected by MCA but also in the perilesional tissue undergoing plastic reorganization.

Stimulation of the dentatothalamocortical pathway can be achieved by targeting its origin in the dentate nucleus, along its axonal projections in the region of the superior cerebellar peduncle, at the level of the thalamus and its projections to the cortex or at the cortex. An advantage of targeting the deep cerebellar nucleus or the cerebello-thalamic projections, however, is that this allows for activation of the pathway early in its course, enabling the capture of the entire (or at least the majority) of the dentate output with a single electrode. In comparison, targeting the thalamus or even the cerebral cortex would require several electrodes
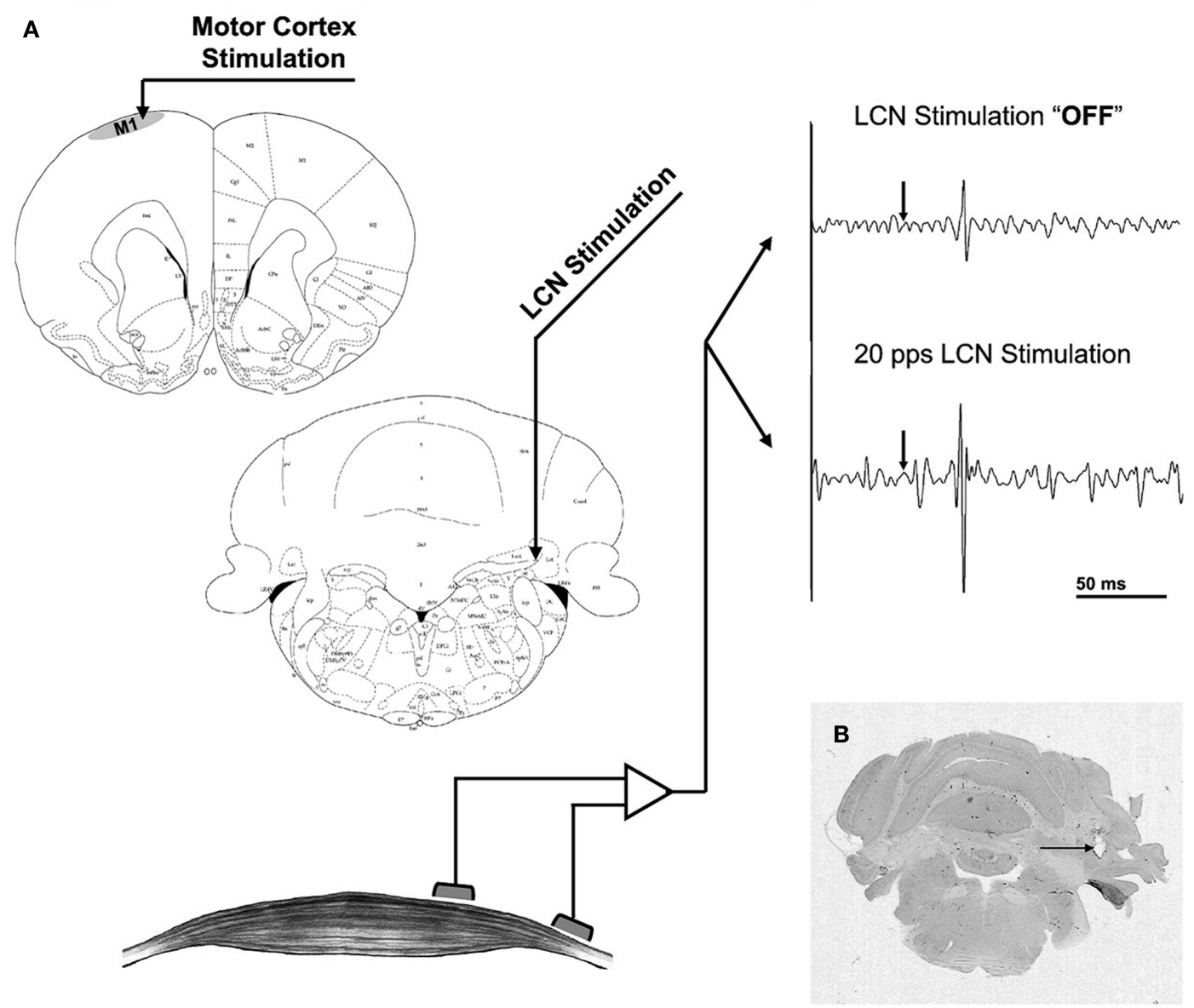

FIGURE 1 | (A) Stimulation and recording set-up. The intracortical microstimulation electrode was placed in the motor cortex (upper left) while MEPs were recorded from the contralateral hamstrings (bottom left). LCN stimulation was delivered via a macroelectrode (center left) and is not coupled to intracortical microstimulation. The raw EMG tracings (upper right) represent a 200-ms segment, comprised of a $50-\mathrm{ms}$ baseline followed by a $150-\mathrm{ms}$ response window. The arrow represents the time of intracortical stimulation. (B) Coronal cut of the rat's cerebellum stained for H\&E. The artifact corresponding to the tip of the macroelectrode targeted at the LCN can be seen (arrow). With permission from Elsevier Limited 72. 
in order to encompass the various regions involved in the pathway. It could perhaps be argued that thalamic stimulation would be advantageous because of its monosynaptic proximity to the cortex, however direct stimulation of the thalamus could interfere with reciprocate thalamocortical rhythms with potentially deleterious effects. As detailed below, our early experiments demonstrated that stimulation of the dentate output can generate robust effects on cortical excitability (Baker et al., 2010).

\section{STIMULATION OF THE DENTATOTHALAMOCORTICAL PATHWAY HAS A FACILITATORY EFFECT ON THE OPPOSITE CEREBRAL HEMISPHERE}

In the 1970s and 1980s, Wright et al. (1984), Davis et al. (1983) and Cooper et al. (1973) attempted to modulate the output of the cerebellum for the treatment of epilepsy, reporting moderate to significant improvements in seizure frequency. Perhaps as a reflection of the available technology at the time, those studies did not attempt to use depth electrodes targeting the deep cerebellar nuclei, but rather used subdural electrode grids placed further "upstream" over the cerebellar cortex. As a therapeutic approach, subdural cerebellar stimulation for epilepsy ultimately fell into disfavor, with subsequent controlled studies unable to replicate the positive results. This failure may have been due, in part, to technical issues related to the ability of a cortical stimulation approach to influence a sufficient proportion of dentatothalamocortical fibers. The leads were placed over the tentorial surface of the cerebellum and thus were able to modulate only a limited fraction of the entire cerebellar output.

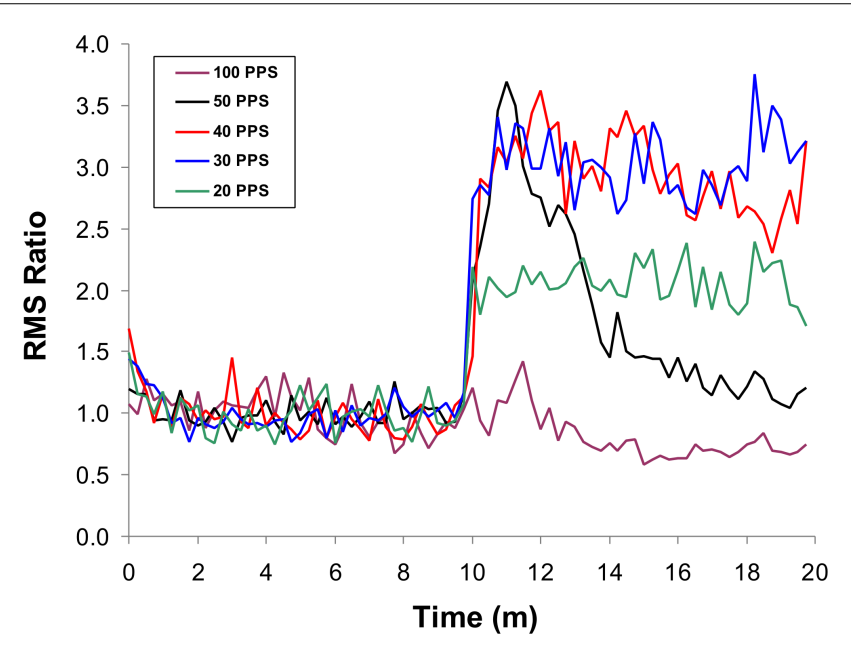

FIGURE 2 | Effects of LCN stimulation on mean MEP amplitude over time, showing frequency dependency of the response. The initial $10 \mathrm{~min}$ of data represent the "off" LCN stimulation condition, followed by 10-min of "on." The effects for each stimulation frequency are shown. All frequency conditions show an initial increase in MEP response magnitude at the start of LCN stimulation, except for $100 \mathrm{~Hz}$. At $50 \mathrm{~Hz}$, the effect is transient, with the response approximating baseline ("off") levels by the end of the 10-min block. A similar but less dramatic pattern is seen for stimulation at $40 \mathrm{~Hz}$. The enhancement is sustained at both 20 and $30 \mathrm{~Hz}$ but more pronounced at $30 \mathrm{~Hz}$. With permission from Elsevier Limited 72.
Over the past decade, the effect of stimulation of the dentatothalamocortical pathway on cortical excitability has been studied in experimental models as well as in human studies (Di Lazzaro et al., 1994a, 1995; Werhahn et al., 1996). Rispal-Padel et al. (1981) used depth electrodes to deliver direct electrical stimulation to the dentate nucleus in baboons and showed that single pulse stimulation elicited ipsilateral motor responses mediated by supra-threshold activation of the thalamus and contralateral motor cortex. Iwata et al. (2004) studied a group of five subjects who underwent high voltage, single pulse direct current cerebellar stimulation over the right mastoid region (aimed at affecting the dentate nucleus). Stimulation was associated with a facilitatory effect on the contralateral hemisphere. Although such studies provide physiological evidence of the excitatory nature of the dentatothalamocortical pathway, they only demonstrate the facilitatory effect associated with intermittent, single pulse stimuli or paired stimuli. As currently applied, neurorehabilitative therapies rely on chronic stimulation, usually coupled with physical training. Hence, it is necessary at first to determine (a) if continuous stimulation of the dentatothalamocortical pathway can produce a sustained facilitatory effect in the contralateral cerebral cortex and (b) how this effect is influenced by changes in stimulation frequency.

\section{FREOUENCY-DEPENDENT EFFECTS OF CHRONIC DENTATOTHALAMOCORTICAL PATHWAY STIMULATION}

We recently examined the effect of chronic stimulation of the dentatothalamocortical pathway on contralateral cortical excitability and facilitation in the rodent model (Baker et al., 2010). Rats were placed under continuous propofol anesthesia and instrumented for a stimulation paradigm involving continuous, asynchronous "conditioning" stimulation of the lateral cerebellar (dentate) nucleus paired with periodic, intracortical microstimulation of the contralateral motor cortex. Subcutaneous electromyographic (EMG) recordings of the hamstring musculature were used to record the MEP response to test stimulation of the contralateral motor cortex at $125 \%$ of motor threshold (Figure 1). Once setup was complete, MEPs were recorded serially, with test pulses delivered approximately every 15-s. The activity of the cerebellar electrode was divided into $10 \mathrm{~min}$ blocks, where stimulation was either OFF or ON. When ON, stimulation was delivered at $80 \%$ of motor threshold for cerebellar stimulation at pulse rates of 20,30, 40, 50, or $100 \mathrm{~Hz}$. The results, summarized in Figure 2, revealed that stimulation at lower frequencies was associated with a sustained facilitative effect on the contralateral cortex as indexed by the magnitude of the MEP (normalized root means square ratio of the electromyographic response). The magnitude of the effect was greatest in the beta band of stimulation frequencies and showed a step-wise reduction in the higher frequencies beginning with $40 \mathrm{~Hz}$. Interestingly, stimulation at $100 \mathrm{~Hz}$ (high frequency stimulation), though initially associated with an increase in cortical excitability (within the first minute of the $10 \mathrm{~min}$ block) ultimately produced a negative net effect on cortical facilitation. Overall, these results demonstrate that stimulation of the dentatothalamocortical pathway can produce a facilitative effect on the contralateral cortical hemisphere and that this effect does not require that the conditioning pulses be time-locked to the cortical activation. 


\section{CHRONIC, BETA BAND STIMULATION OF THE DENTATOTHALAMOCORTICAL PATHWAY ENHANCES MOTOR RECOVERY FOLLOWING LARGE VOLUME CEREBRAL ISCHEMIA}

Translational investigation in stroke rehabilitation often relies on animal models of disease. Currently there are several methods and variations for inducing cerebral ischemia in rats, each with advantages and disadvantages (Yanamoto et al., 2003; Kleim et al., 2007). The advantages of a small, well-controlled stroke model include a lower mortality rate and ample sparing of perilesional cortex to serve as the substrate for therapeutically facilitated functional reorganization. However, this type of model also creates a translational gap as the results may not be relevant to lesscontrolled and larger spontaneous strokes observed in humans (Plow et al., 2009). Our initial approach was to evaluate the rehabilitative potential of this novel therapy in large ischemic strokes due to its translational impact. The stroke model selected was the three-vessel occlusion model (Yanamoto et al., 2003) involving permanent microsurgical ligation of the middle cerebral artery combined with 30-min occlusion followed by reperfusion of both common carotid arteries. This model, after initial validation in our lab, creates a large lesion affecting most of the cortex anterior to the coronal suture, with approximately one-third of tissue preserved at the level of the bregma (Figure 3). This lesion was deemed large enough to mimic the area damaged by a middle cerebral artery infarction, though the majority of the parietal cortex was preserved as was the thalamus and basal ganglia. Sparing the parietal cortex, an area that receives projections from the dentatothalamocortical pathway, allowed for the potential participation of this region in post-stroke reorganization and rehabilitation. Preservation of the thalamus was considered important in the context of this approach, given that its injury could diminish the effect of the therapy by knocking out an important relay of the dentatothalamocortical pathway. All surviving animals were implanted with lateral cerebellar nucleus macroelectrodes and were randomized to either sham stimulation or to stimulation at 10,20 , or $50 \mathrm{~Hz}$, with amplitude set at $80 \%$ of the motor threshold for cerebellar stimulation. Although a trend for improvement was seen in the $50 \mathrm{~Hz}$ stimulation group, only rats stimulated in the beta band showed significant improvement in motor function as measured by performance on the Montoya staircase task (Machado et al., 2009). The results indicate that there is frequency-specificity to dentatothalamocortical stimulation related motor rehabilitation. Importantly, the same frequency band - beta - that was found to optimally enhance cortical excitability in our acute, electrophysiological studies was also associated with significant rehabilitative gains. Our results thus far suggest that beta band dentatothalamocortical stimulation has post-stroke motor recovery rehabilitative potential that may be mediated through enhancement of perilesional cortical excitability. However, a causal link has not yet been demonstrated as the evidence acquired to date is only correlative in nature and involves differences in experimental design that must be addressed.

\section{HUMAN TRANSLATION}

Neurostimulation devices have been implanted in the central nervous system for several decades and DBS is currently a

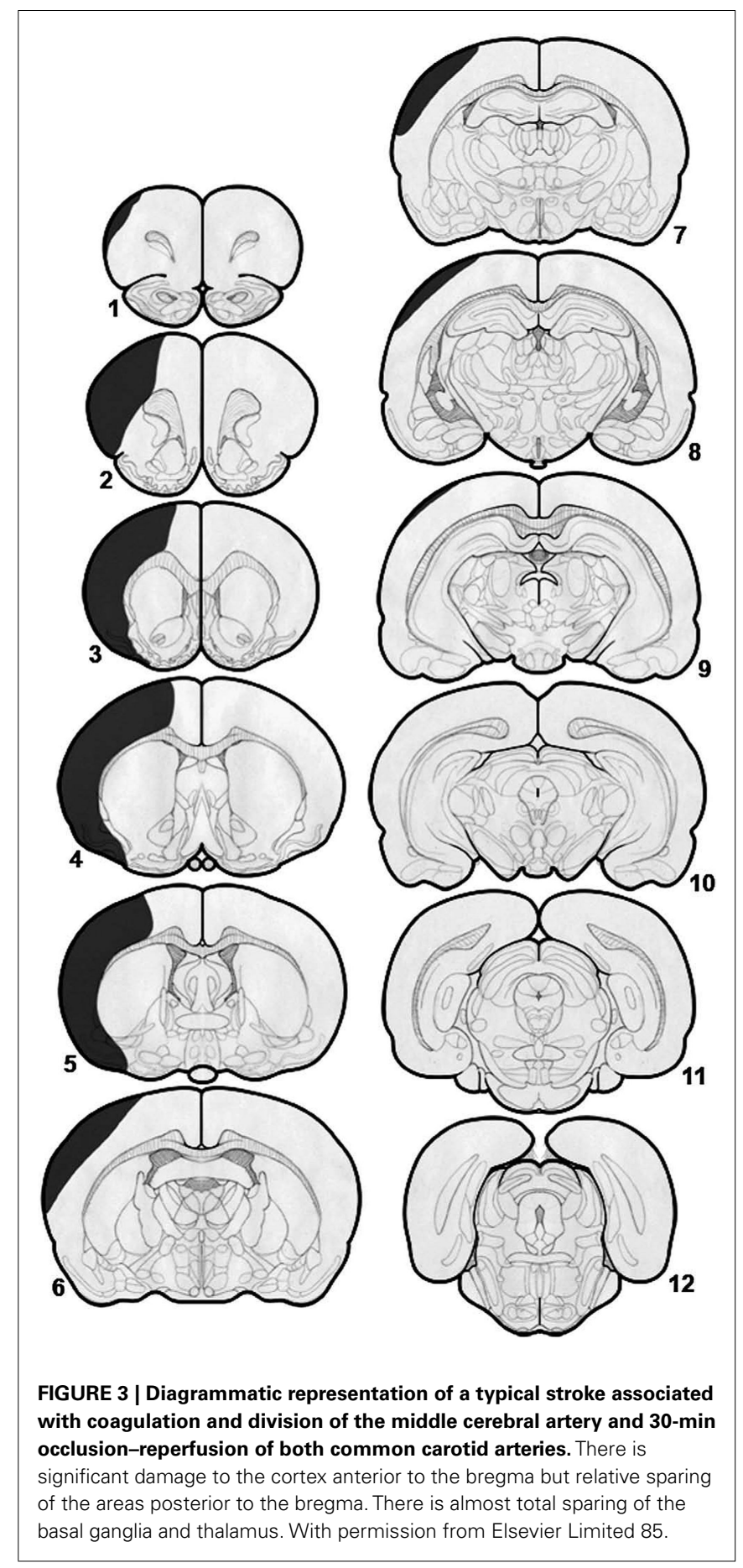

routine procedure that is approved in the United States for the symptomatic management of Parkinson's disease and essential tremor. It is also approved under Humanitarian Device Exemption for the treatment of dystonia as well as obsessive-compulsive disorder. As such, the safety profile of the implantable materials is well established and the chronic stimulation with charge density below $30 \mu \mathrm{C} / \mathrm{cm}^{2} /$ phase is generally regarded as safe. Although there will be differences related to surgical targeting as well as 
stimulation protocols in translating the proposed approach to clinical use, we argue that DBS of the dentatothalamocortical pathway represents a viable approach for enhancing motor rehabilitation following stroke. The current data based on rodent models of cerebral ischemia and sustained stimulation of the lateral cerebellar nucleus suggest that stimulation in the beta band is likely the most efficient for post-stroke neurorehabilitation, though additional stimulation parameters should be evaluated and the findings need to be validated across species. Issues related to timing of poststroke stimulation onset and duration of the effects of chronic stimulation remain unknown and need to be addressed in future research.

\section{RESEARCH SUPPORT}

5R01HD061363.

\section{DISCLOSURE}

Machado and Baker disclose ownership interest in IntElect Medical (acquired in 2011 by Boston Scientific), ATI and Cardionomics. Machado discloses consulting for Monteris Medical.

\section{REFERENCES}

Abe, K., Ukita, H., Yorifuji, S., and Yanagihara, T. (1997). Crossed cerebellar diaschisis in chronic Broca's aphasia. Neuroradiology 39, 624-626.

Adkins, D. L., Campos, P., Quach, D., Borromeo, M., Schallert, K., and Jones, T. A. (2006). Epidural cortical stimulation enhances motor function after sensorimotor cortical infarcts in rats. Exp. Neurol. 200, 356-370.

Adkins, D. L., Hsu, J. E., and Jones, T. A. (2008). Motor cortical stimulation promotes synaptic plasticity and behavioral improvements following sensorimotor cortex lesions. Exp. Neurol. 212, 14-28.

Adkins-Muir, D. L., and Jones, T. A. (2003). Cortical electrical stimulation combined with rehabilitative training: enhanced functional recovery and dendritic plasticity following focal cortical ischemia in rats. Neurol. Res. 25, 780-788.

Baker, K. B., Schuster, D., Cooperrider, J., and Machado, A. G. (2010). Deep brain stimulation of the lateral cerebellar nucleus produces frequencyspecific alterations in motor evoked potentials in the rat in vivo. Exp. Neurol. 226, 259-264.

Baron, J. C. (1993). Crossed cerebellar diaschisis and atrophy: the role of intractable seizures. AJR Am. J. Roentgenol. 160, 1152.

Blicher, J. U., Jakobsen, J., Andersen, G., and Nielsen, J. F. (2009). Cortical excitability in chronic stroke and modulation by training: a TMS study. Neurorehabil. Neural. Repair 23, 486-493.

Brown, J. A., Lutsep, H., Cramer, S. C., and Weinand, M. (2003). Motor cortex stimulation for enhancement of recovery after stroke: case report. Neurol. Res. 25, 815-818.

Brown, J. A., Lutsep, H. L., Weinand, M., and Cramer, S. C. (2008). Motor cortex stimulation for the enhancement of recovery from stroke: a prospective, multicenter safety study. Neurosurgery 62(Suppl. 2), 853-862.

Brunberg, J. A., Frey, K. A., Horton, J. A., and Kuhl, D. E. (1992). Crossed cerebellar diaschisis: occurrence and resolution demonstrated with PET during carotid temporary balloon occlusion. AJNR Am. J. Neuroradiol. 13, 58-61.

Butler, A. J., and Wolf, S. L. (2007). Putting the brain on the map: use of transcranial magnetic stimulation to assess and induce cortical plasticity of upper-extremity movement. Phys. Ther. 87, 719-736.

Cooper, I. S., Amin, I., and Gilman, S. (1973). The effect of chronic cerebellar stimulation upon epilepsy in man. Trans. Am. Neurol. Assoc. 98, 192-196.

Davis, R., Gray, E., Engle, H., and Dusnak, A. (1983). Reduction of intractable seizures using cerebellar stimulation. Appl. Neurophysiol. 46, 57-61.

De Reuck, J., Decoo, D., Lemahieu, I., Strijckmans, K., Goethals, P., and Van Maele, G. (1997). Crossed cerebellar diaschisis after middle cerebral artery infarction. Clin. Neurol. Neurosurg. 99, 11-16.

Di Lazzaro, V., Molinari, M., Restuccia, D., Leggio, M. G., Nardone, R., Fogli, D., and Tonali, P. (1994a). Cerebrocerebellar interactions in man: neurophysiological studies in patients with focal cerebellar lesions. Electroencephalogr. Clin. Neurophysiol. 93, 27-34.

Di Lazzaro, V., Restuccia, D., Molinari, M., Leggio, M. G., Nardone, R., Fogli, D., and Tonali, P. (1994b). Excitability of the motor cortex to magnetic stimulation in patients with cerebellar lesions. J. Neurol. Neurosurg. Psychiatr. 57, 108-110.

Di Lazzaro, V., Restuccia, D., Nardone, R., Leggio, M. G., Oliviero, A., Profice, P., Tonali, P., and Molinari, M. (1995). Motor cortex changes in a patient with hemicerebellectomy. Electroencephalogr. Clin. Neurophysiol. 97, 259-263.
Dum, R. P., Li, C., and Strick, P. L. (2002). Motor and nonmotor domains in the monkey dentate. Ann. N. Y. Acad. Sci. 978, 289-301.

Dum, R. P., and Strick, P. L. (2003). An unfolded map of the cerebellar dentate nucleus and its projections to the cerebral cortex. J. Neurophysiol. 89, 634-639.

Floel, A., and Cohen, L. G. (2010). Recovery of function in humans: cortical stimulation and pharmacological treatments after stroke. $\mathrm{Neu}$ robiol. Dis. 37, 243-251.

Flores, L. G. II, Futami, S., Hoshi, H., Nagamachi, S., Ohnishi, T., Jinnouchi, S., and Watanabe, K. (1995). Crossed cerebellar diaschisis: analysis of iodine-123-IMP SPECT imaging. J. Nucl. Med. 36, 399-402.

Follett, K. A., Weaver, F. M., Stern, M. Hur, K., Harris, C. L., Luo, P., Marks, W. J. Jr., Rothlind, J., Sagher, O., Moy, C., Pahwa, R., Burchiel, K., Hogarth, P., Lai, E. C., Duda, J. E., Holloway, K., Samii, A., Horn, S., Bronstein, J. M., Stoner, G., Starr, P. A., Simpson, R., Baltuch, G., De Salles, A., Huang, G. D., and Reda, D. J. (2010). Pallidal versus subthalamic deep-brain stimulation for Parkinson's disease. N. Engl. J. Med. 362, 2077-2091.

Fregni, F., Boggio, P. S., Mansur, C. G. Wagner, T., Ferreira, M. J., Lima, M. C., Rigonatti, S. P., Marcolin, M. A., Freedman, S. D., Nitsche, M. A., and Pascual-Leone, A. (2005). Transcranial direct current stimulation of the unaffected hemisphere in stroke patients. Neuroreport 16, 1551-1555.

Fregni, F., Boggio, P. S., Valle, A. C., Rocha, R. R., Duarte, J., Ferreira, M. J., Wagner, T., Fecteau, S., Rigonatti, S. P., Riberto, M., Freedman, S. D., and Pascual-Leone, A. (2006). A sham-controlled trial of a 5day course of repetitive transcranial magnetic stimulation of the unaffected hemisphere in stroke patients. Stroke 37, 2115-2122.

Frost, S. B., Barbay, S., Friel, K. M., Plautz, E. J., and Nudo, R. J. (2003). Reorganization of remote cortical regions after ischemic brain injury: a potential substrate for stroke recovery. J. Neurophysiol. 89, 3205-3214.

Glees, P., and Cole, J. (1952). Ipsilateral representation in the cerebral cortex; its significance in relation to motor function. Lancet 1, 1191-1192.

Harvey, R. L., and Winstein, C. J. (2009). Design for the everest randomized trial of cortical stimulation and rehabilitation for arm function following stroke. Neurorehabil. Neural. Repair 23, 32-44.

Holsheimer, J., Nguyen, J. P., Lefaucheur, J. P., and Manola, L. (2007). Cathodal, anodal or bifocal stimulation of the motor cortex in the management of chronic pain? Acta Neurochir. Suppl. 97, 57-66.

Huang, M., Harvey, R. L., Stoykov, M. E., Ruland, S., Weinand, M., Lowry, D., and Levy, R. (2008). Cortical stimulation for upper limb recovery following ischemic stroke: a small phase II pilot study of a fully implanted stimulator. Top. Stroke. Rehabil. 15, 160-172.

Hummel, F., Celnik, P., Giraux, P., Floel, A., Wu, W. H., Gerloff, C., and Cohen, L. G. (2005). Effects of non-invasive cortical stimulation on skilled motor function in chronic stroke. Brain 128, 490-499.

Hummel, F., and Cohen, L. G. (2005). Improvement of motor function with noninvasive cortical stimulation in a patient with chronic stroke. Neurorehabil. Neural. Repair 19, 14-19.

Ishihara, M., Kumita, S., Mizumura, S., and Kumazaki, T. (1999). Crossed cerebellar diaschisis: the role of motor and premotor areas in functional connections. J. Neuroimaging 9, 30-33.

Iwata, N. K., Hanajima, R., Furubayashi, T., Terao, Y., Uesugi, H., Shiio, Y., Enomoto, H., Mochizuki, H., Kanazawa, I., and Ugawa, Y. (2004). Facilitatory effect on the motor cortex by electrical stimulation over the cerebellum in humans. Exp. Brain Res. 159, 418-424. 
Johansen-Berg, H., Rushworth, M. F., Bogdanovic, M. D., Kischka, U., Wimalaratna, S., and Matthews, P. M. (2002). The role of ipsilateral premotor cortex in hand movement after stroke. Proc. Natl. Acad. Sci. U.S.A. 99, 14518-14523.

Kim, S. E., Choi, C. W., Yoon, B. W., Chung, J. K., Roh, J. H., Lee, M. C., and Koh, C. S. (1997). Crossed-cerebellar diaschisis in cerebral infarction: technetium-99mHMPAO SPECT and MRI. J. Nucl. Med. 38, 14-19.

Kleim, J. A., Barbay, S., and Nudo, R. J. (1998). Functional reorganization of the rat motor cortex following motor skill learning. J. Neurophysiol. 80, 3321-3325.

Kleim, J. A., Boychuk, J. A., and Adkins, D. L. (2007). Rat models of upper extremity impairment in stroke. ILAR J. 48, 374-384.

Levy, R., Ruland, S., Weinand, M., Lowry, D., Dafer, R., and Bakay, R. (2008). Cortical stimulation for the rehabilitation of patients with hemiparetic stroke: a multicenter feasibility study of safety and efficacy. J. Neurosurg. 108, 707-714.

Liepert, J. (2006). Motor cortex excitability in stroke before and after constraint-induced movement therapy. Cogn. Behav. Neurol. 19, 41-47.

Liepert, J., Bauder, H., Wolfgang, H. R., Miltner, W. H., Taub, E., and Weiller, C. (2000). Treatmentinduced cortical reorganization after stroke in humans. Stroke 31, 1210-1216.

Liepert, J., Uhde, I., Graf, S., Leidner, O., and Weiller, C. (2001). Motor cortex plasticity during forced-use therapy in stroke patients: a preliminary study. J. Neurol. 248, 315-321.

Lin, W. Y. (1997). Crossed cerebellar diaschisis: related to lesion location or disease duration? J. Nucl. Med. 38 , 2006.

Lin, Y. C., Ko, T. L., Shih, Y. H., Lin, M. Y., Fu, T. W., Hsiao, H. S., Hsu, J. Y., and Fu, Y. S. (2011). Human umbilical mesenchymal stem cells promote recovery after ischemic stroke. Stroke 42, 2045-2053.

Machado, A., Azmi, H., and Rezai, A. R. (2007). Motor cortex stimulation for refractory benign pain. Clin. Neurosurg. 54, 70-77.

Machado, A. G., Baker, K. B., Schuster, D., Butler, R. S., and Rezai, A. (2009). Chronic electrical stimulation of the contralesional lateral cerebellar nucleus enhances recovery of motor function after cerebral ischemia in rats. Brain Res. 1280, 107-116.

Machado, A., Fernandez, H. H., and Deogaonkar, M. (2012). Deep brain stimulation: what can patients expect from it? Cleve. Clin. J. Med. 79, 113-120.

Manola, L., Holsheimer, J., Veltink, P., and Buitenweg, J. R. (2007). Anodal vs cathodal stimulation of motor cortex: a modeling study. Clin. Neurophysiol. 118, 464-474.

Miura, H., Nagata, K., Hirata, Y., Satoh, Y., Watahiki, Y., and Hatazawa, J. (1994). Evolution of crossed cerebellar diaschisis in middle cerebral artery infarction. J. Neuroimaging 4 , 91-96.

Nathan, M. A., Bushnell, D. L., Kahn, D., Simonson, T. M., and Kirchner, P. T. (1994). Crossed cerebellar diaschisis associated with balloon test occlusion of the carotid artery. Nucl. Med. Commun. 15, 448-454.

Nudo, R. J., and Milliken, G. W. (1996). Reorganization of movement representations in primary motor cortex following focal ischemic infarcts in adult squirrel monkeys. J. Neurophysiol. 75, 2144-2149.

Pantano, P., Baron, J., Samson, Y., Bousser, M., Derouesne, C., and Comar, D. (1986). Crossed cerebellar diaschisis. Brain 109, 677-694.

Pantano, P., Lenzi, G. L., Guidetti, B., Di Piero, V., Gerundini, P., Savi, A. R., Fazio, F., and Fieschi, C. (1987). Crossed cerebellar diaschisis in patients with cerebral ischemia assessed by SPECT and 123IHIPDM. Eur. Neurol. 27, 142-148.

Penfield, W., and Rasmussen, T. (1950). The Cerebral Cortex of Man. New York: Macwilliam.

Plautz, E. J., Barbay, S., Frost, S. B., Friel, K. M., Dancause, N., Zoubina, E. V., Stowe, A. M., Quaney, B. M., and Nudo, R. J. (2003). Post-infarct cortical plasticity and behavioral recovery using concurrent cortical stimulation and rehabilitative training: a feasibility study in primates. Neurol. Res. 25, 801-810.

Plow, E. B., Carey, J. R., Nudo, R. J., and Pascual-Leone, A. (2009). Invasive cortical stimulation to promote recovery of function after stroke: a critical appraisal. Stroke 40, 1926-1931.

Ray, C. D., and Burton, C. V. (1980). Deep brain stimulation for severe, chronic pain. Acta Neurochir. Suppl. (Wien) 30, 289-293.
Reivich, M. (1992). Crossed cerebellar diaschisis. AJNR Am. J. Neuroradiol. 13, 62-64.

Rispal-Padel, L., Cicirata, F., and Pons, C. (1981). Contribution of the dentato-thalamo-cortical system to control of motor synergy. Neurosci. Lett. 22, 137-144.

Roger, V. L., Go, A. S., Lloyd-Jones, D. M., Adams, R. J., Berry, J. D. Brown, T. M., Carnethon, M. R., Dai, S., De Simone, G., Ford, E. S., Fox C. S., Fullerton, H. J., Gillespie, C., Greenlund, K. J., Hailpern, S. M. Heit, J. A., Ho, P. M., Howard, V. J., Kissela, B. M., Kittner, S. J., Lackland, D. T., Lichtman, J. H., Lisabeth, L. D., Makuc, D. M., Marcus, G. M. Marelli, A., Matchar, D. B., Mcdermott, M. M., Meigs, J. B., Moy, C. S., Mozaffarian, D., Mussolino, M. E., Nichol, G., Paynter, N. P., Rosamond, W. D., Sorlie, P. D., Stafford, R. S., Turan, T. N., Turner, M. B. Wong, N. D., and Wylie-Rosett, J. (2011). Heart disease and stroke statistics - 2011 update: a report from the American Heart Association. Circulation 123, e18-e209.

Savitz, S. I., Chopp, M., Deans, R. Carmichael, S. T., Phinney, D. and Wechsler, L. (2011). Stem cell therapy as an emerging paradigm for stroke (STEPS) II. Stroke 42, 825-829.

Seitz, R. J., Hoflich, P., Binkofski, F., Tellmann, L., Herzog, H., and Freund, H. J. (1998). Role of the premotor cortex in recovery from middle cerebral artery infarction. Arch. Neurol. 55, 1081-1088.

Siegfried, J., Lazorthes, Y., and Sedan, R. (1980). Indications and ethical considerations of deep brain stimulation. Acto Neurochir. Suppl. (Wien) 30 269-274.

Srinivasan, A., Miller, W., Stys, P., and Goyal, M. (2004). Crossed cerebellar diaschisis in stroke. Neurology 62 , 2130.

Takasawa, M., Watanabe, M., Yamamoto, S., Hoshi, T., Sasaki, T., Hashikawa, K., Matsumoto, M., and Kinoshita, N. (2002). Prognostic value of subacute crossed cerebellar diaschisis: single-photon emission CT study in patients with middle cerebral artery territory infarct. AJNR Am. J. Neuroradiol. 23 189-193.

Takeuchi, N., Chuma, T., Matsuo, Y., Watanabe, I., and Ikoma, K. (2005). Repetitive transcranial magnetic stimulation of contralesional primary motor cortex improves hand function after stroke. Stroke 36 2681-2686.
Tanaka, M., Kondo, S., Hirai, S., Ishiguro, K., Ishihara, T., and Morimatsu, M. (1992). Crossed cerebellar diaschisis accompanied by hemiataxia: a PET study. $J$. Neurol. Neurosurg. Psychiatr. 55, 121-125.

Theilig, S., Podubecka, J., Bosl, K., Wiederer, R., and Nowak, D. A (2011). Functional neuromuscular stimulation to improve severe hand dysfunction after stroke: does inhibitory rTMS enhance therapeutic efficiency? Exp. Neurol. 230, 149-155.

Tracey, D. J., Asanuma, C., Jones, E. G., and Porter, R. (1980). Thalamic relay to motor cortex: afferent pathways from brain stem, cerebellum, and spinal cord in monkeys. J. Neurophysiol. 44, 532-554.

Tsubokawa, T., Katayama, Y., Yamamoto, T., Hirayama, T., and Koyama, S. (1991a). Chronic motor cortex stimulation for the treatment of central pain. Acta Neurochir. Suppl. (Wien) 52, 137-139.

Tsubokawa, T., Katayama, Y., Yamamoto, T., Hirayama, T., and Koyama, S. (1991b). Treatment of thalamic pain by chronic motor cortex stimulation. Pacing Clin. Electrophysiol. 14, 131-134.

von Monakow, C. (1950). "Localization of brain functions," in Some Papers on the Cerebral Cortex, ed. G. V. Bonin (Springfield: Charles Thomas), 231-250.

Werhahn, K. J., Taylor, J., Ridding, M., Meyer, B. U., and Rothwell, J. C. (1996). Effect of transcranial magnetic stimulation over the cerebellum on the excitability of human motor cortex. Electroencephalogr. Clin. Neurophysiol. 101, 58-66.

Wright, G. D., Mclellan, D. L., and Brice, J. G. (1984). A double-blind trial of chronic cerebellar stimulation in twelve patients with severe epilepsy. J. Neurol. Neurosurg. Psychiatr. 47, 769-774.

Yanamoto, H., Nagata, I., Niitsu, Y., Xue, J. H., Zhang, Z., and Kikuchi, H. (2003). Evaluation of MCAO stroke models in normotensive rats: standardized neocortical infarction by the 3VO technique. Exp. Neurol. 182, 261-274.

Zago, S., Ferrucci, R., Fregni, F., and Priori, A. (2008). Bartholow, Sciamanna, Alberti: pioneers in the electrical stimulation of the exposed human cerebral cortex. Neuroscientist 14 521-528. 
Conflict of Interest Statement: The authors declare that the research was conducted in the absence of any commercial or financial relationships that could be construed as a potential conflict of interest.
Received: 01 February 2012; accepted: 28 April 2012; published online: 21 May 2012.

Citation: Machado $A$ and Baker KB (2012) Upside down crossed cerebellar diaschisis: proposing chronic stimulation of the dentatothalamocortical pathway for post-stroke motor recovery. Front. Integr. Neurosci. 6:20. doi: 10.3389/fnint.2012.00020

Copyright (c) 2012 Machado and Baker. This is an open-access article distributed under the terms of the Creative Commons Attribution Non Commercial License, which permits non-commercial use, distribution, and reproduction in other forums, provided the original authors and source are credited. 